$2016-12$

\title{
Giving voice to optimism and hope for the future of nursing.
}

\section{Rook, $\mathrm{H}$}

http://hdl.handle.net/10026.1/13037

10.1016/j.colegn.2016.11.002

Collegian

Elsevier

All content in PEARL is protected by copyright law. Author manuscripts are made available in accordance with publisher policies. Please cite only the published version using the details provided on the item record or document. In the absence of an open licence (e.g. Creative Commons), permissions for further reuse of content should be sought from the publisher or author. 
Rook H Coombs MA 2016. Giving voice to optimism and hope for the future of nursing. Collegian December 2016 Volume 23, Issue 4, Pages 397-398

Author copy. Accepted for publication 1 September 2016

DOI: 10.1016/j.colegn.2016.11.002

\section{Giving voice to optimism and hope for the future of nursing}

Rook $\mathrm{H}$

Lecturer, Graduate School of Nursing Midwifery and Health

Victoria University of Wellington, Wellington, New Zealand

Coombs MA

Professor of Clinical Nursing (Critical Care)

Victoria University of Wellington, Wellington, New Zealand

It is true that there are many instances where the nursing voice is absent. For example, the voice at the bedside when advocating for vulnerable patients; the voice at ward meetings when negotiating new changes to be introduced; and the voice at Executive Board level when standing up for the rights of nurses whilst engaged in complex health care agendas. Being able to articulate the position of nursing, and of nurses, is not always simple. We know why, and how, this suppression has occurred through well-rehearsed arguments that draw on the historical origins of nursing, the late professionalisation of nurses, and the impact of gender. However, even with this understanding, it continues to be a challenge to get the nursing voice heard and, as stated by Sanchia Aranda (2015) in her Collegian Editorial last year 'we still have to work to break the silence'.

After reading Aranda's piece, it made us reflect on our view of the nursing voice and how we have recently experienced it through the voices of nurse participants in research projects we have undertaken and in the voices of post-graduate students that we have worked with. Whilst there were times of silence, of missed opportunities in these encounters (and we include ourselves in that statement), there were also times of undeniable optimism and hope for the future. This came through in the many positive examples of how nurses spoke of, and about, practice. Optimism about the future of nursing evident through the clear way that the nursing contribution to care was spoken of, and hope for the profession in the way that commitment to nursing values underpinned much of what was being said by nurses.

During research conducted with nurses as participants, we have been privileged to hear of the many stories that expressed optimism in the profession: of the times that nurses 'went the extra mile' for patients, and for their colleagues. Nurses who were able to achieve the unachievable in order to meet patient's last wishes at end of life; of those who skilfully worked with and amongst clinical teams to ensure that both patients and family wishes were heard and respected; and of those who, against considerable pressure, demonstrated professional integrity when supporting nursing colleagues during challenging intra and inter-professional communication. Each of these is a superb example of hope for the future of nursing. 
In preparing for this Editorial, we also reflected on comments made to us by students over the past year. Recently, we asked a group of nurses about what qualities they wanted to hold as a nurse. Here are some of the amazing and inspiring statements, used with permission: I [will] have a commitment to the community; I will be kind and care; I will advocate; I will have a duty of care; I have professional responsibility; I will be self-aware; I will endeavour to uphold public trust; I will be an educated professional; I will be passionate and compassionate; I will have cultural safety; I will support my peers; I will take care of myself and therefore care for others; I will be a good role model; I will be a lifelong learner; I will look at the big picture. We have seen such enthusiasm, passion and excitement then translate into practice during the learning of new knowledge and skills. We have heard accounts of the difference made to patients, of the utilisation of advanced assessment skills in detecting patient problems thereby alleviating distress, and of developing new clinical practice guidelines that improve patient safety and quality improvement. Such affirmations and exemplars surely brings optimism for what nurses can bring to patients and the wider community in improving health outcomes.

Bringing a sense of hope into a situation is often evidenced in our actions; of what we do and what we say. So how do we convey optimism and hope in the reality of practice? For us, it is about how we role model, how we give voice to strong leadership and demonstrate professional practice underpinned by clear values. Sometimes we think that using this 'voice' is about being centre stage. That it is about taking on the 'giants' of the health care world, whoever they may be, our senior colleagues, our junior colleagues who may be using bullying behaviour, or our managers. Whilst that is certainly one way to be heard, it is a courageous and forthright way requiring confidence, composure and experience: but it is not the only way.

There are many other ways that we can say what needs to be said, and thereby bring optimism and hope. Ways that give rise to a quieter but none the less, effective voice. Such as using a well-timed and well-constructed question to draw attention to an issue, or the subtle presentation of an alternative argument for consideration in the face of a polarised view, or negotiation in an argumentative situation to achieve a win-win solution. The way we behave gives testament to, or refutes core professional nursing values. Being clear about and articulating these values is critical to the expression of our professional voice and our professional self-confidence. Through our actions we can exemplar giving voice to nursing. Each of the above behaviours, whilst not so dramatic as standing alone and defending a case, are all examples of how nurses can use their voice. Some of these techniques may be more developed in our individual repertoires and there will be those that we are more comfortable with using. Some may work better in certain circumstances than others. Of course these skills take time to be developed and refine and how we use these is influenced by many factors including age, level of experience, and position and power in our role. Yet they are all powerful strategies that can be used to give expression to the nursing voice.

Debate about the use of optimism and hope in nursing is not just another facet of the positive psychology movement that we are seeing. We are beginning to understand more about the importance of holding a position of optimism and hope in the roles that we hold. There is a developing evidence base that identifies how resilience (Glass 2009) and improved performance (Luthans et al., 2008) are all positively impacted on if nurses are optimistic and have hope. Therefore to realise these benefits and give voice to optimism and hope, we need to be clear about how we value the contribution of nursing to patient care and to the wider health economy. We need to think about and acknowledge the subtler ways of giving voice and of increasing our repertoire with these skills. We need to develop our ability to read and respond to different situations to make the nursing voice heard. It beholds us all to reflect on our behaviour and to think about how we, explicitly or 
implicitly, use our voice to articulate optimism and hope for the future of health care delivery, and for nursing.

\section{REFERENCES}

Aranda S 2015. We still have to work to break the silence. Collegian (2015) 22, 351-352.

Glass N. 2009. An investigation of nurses' and midwives' academic/clinical workplaces: a healing model to improve and sustain hope, optimism, and resilience in professional practice. Holist Nurs Pract. 23; 3: 158-70. doi: 10.1097/HNP.0b013e3181a056c4.

Luthans KW, Lesback SA, Lesback RR. 2008. Positivity in healthcare. Relation of optimism to performance. Journal of Health Organization and Management 22; 2: 178-188. 